\title{
Commentary: Per oral endoscopic myotomy (POEM): Should it now be considered the first-line therapeutic approach for patients with achalasia?
}

\author{
Piers R. Boshier, MRCS, PhD, ${ }^{\mathrm{a}, \mathrm{b}}$ and Donald E. Low, FACS, FRCS(C) ${ }^{\mathrm{a}}$
}

\footnotetext{
From the ${ }^{\mathrm{a} D e p a r t m e n t}$ of Thoracic Surgery and Thoracic Oncology, Virginia Mason Medical Center, Seattle, Wash; and ${ }^{\mathrm{b}}$ Department of Surgery and Cancer, Imperial College London, London, United Kingdom. Disclosures: Authors have nothing to disclose with regard to commercial support.

Received for publication Dec 26, 2018; accepted for publication Dec 28, 2018; available ahead of print June 27, 2019.

Address for reprints: Donald E. Low, FACS, FRCS(C), Department of Thoracic Surgery and Thoracic Oncology, Virginia Mason Medical Center, 1100 9th Ave, Seattle, WA 98111 (E-mail: Donald.Low@ virginiamason.org). J Thorac Cardiovasc Surg 2019;158:953-802

$0022-5223 / \$ 36.00$

Copyright (c) 2019 by The American Association for Thoracic Surgery

https://doi.org/10.1016/j.jtcvs.2018.12.091
}

Why should we be assessing another treatment approach for patients with achalasia? Historically, we have had 2 tried-and-tested treatments for achalasia, 1 endoscopic and 1 surgical, with excellent track records for efficacy and safety. Graded pneumatic dilatation has a welldocumented long-term success rate for symptomatic improvement ranging from $82 \%$ to $86 \%$, although $25 \%$ to $33 \%$ of patients will require multiple dilatations within 4 to 5 years. ${ }^{1}$ Laparoscopic Heller myotomy (LHM) is an elegant and well-tolerated surgical procedure that successfully addresses dysphagia long term in $85 \%$ to $95 \%$ of patients with type I and II achalasia ${ }^{2}$ while at the same procedure addressing the known side effect of lower esophageal sphincter disruption, specifically gastroesophageal reflux disease, with an incomplete fundoplication.

In their institutional review of outcomes at the Cleveland Clinic of per oral endoscopic myotomy (POEM), reported in their article in this issue of the Journal, "Per Oral Endoscopic Myotomy (POEM): Another Tool in the Toolbox," Raja and colleagues ${ }^{3}$ justify the further pursuit of a third treatment approach. They have demonstrated that, despite the learning curve, POEM was carried out safely with profound postprocedural improvements in Eckardt scores and timed barium esophagograms. Their results support previous publications documenting medium-term success rates of POEM of $88 \% .{ }^{4}$ Their treatment algorithm takes a stepwise approach to treatment of patients with type I and II achalasia. In comparison, the 2018 International Society for Diseases of the Esophagus achalasia guidelines ${ }^{5}$ indicated equivalency between POEM and LHM for types I and II and suggests superiority of POEM for type III achalasia. This has led many centers, including our own, to adopt POEM as first-line treatment. In fact, in our institution, the most common reason currently for carrying out one of our

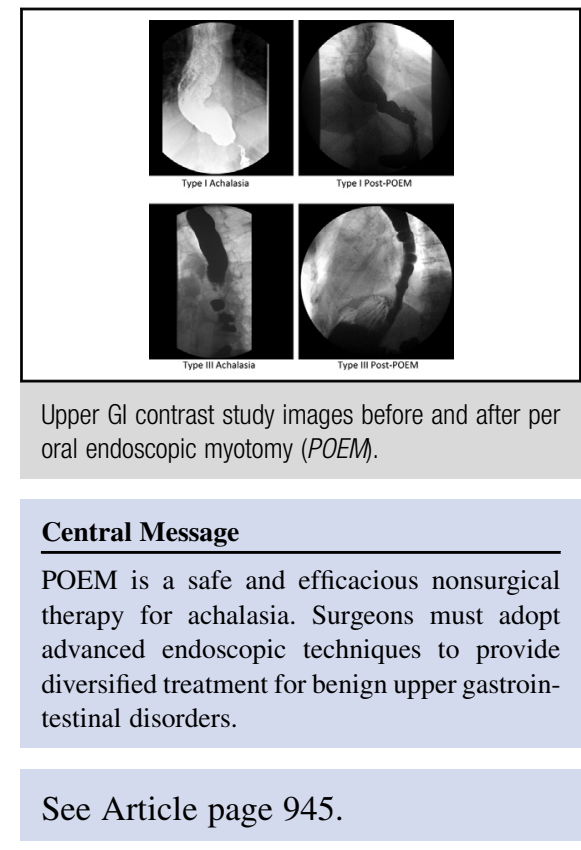

favorite surgical procedures, LHM, is the inability to obtain insurance coverage for POEM.

Are there any other reasons for POEM achieving this lofty status in a relatively short period? The answer is, of course, yes! POEM provides an endoscopic approach to achalasia treatment that, unlike graded pneumatic dilatation, provides a controlled myotomy. It also offers an opportunity to adjust the myotomy in accordance with the findings of high-resolution manometry and the various Chicago classifications for achalasia. It requires skills that are directly applicable in other clinical conditions, such as gastric POEM for gastroparesis. Finally, POEM has been shown to be an excellent therapeutic option for complex presentations, such as failed previous LHM, megaesophagus, and Chagas disease.

Is it all good news? As is pointed out by Raja and colleagues, ${ }^{3}$ postprocedural gastroesophageal reflux disease has been previously identified in $20 \%$ to $46 \%$ of patients ${ }^{6}$ and in $50 \%$ of their series. This important side effect requires ongoing assessment and may warrant initiation of post-POEM surveillance endoscopies to identify patients requiring long-term acid suppression.

Finally, we congratulate our surgical colleagues at the Cleveland clinic for establishing a very successful POEM 
program at their institution. Surgeons must become comfortable with these evolving endoscopic therapies and not abrogate the treatment of achalasia and other gastrointestinal diseases to our gastroenterology colleagues.

In summary, POEM should be considered a first-line therapeutic approach for patients with achalasia. Even in the absence of randomized, controlled trials, the procedure has been introduced safely and demonstrated outcomes at least equivalent to those of graded pneumatic dilatation and LHM. Surgeons interested in the treatment of upper gastrointestinal disorders need to adopt advanced endoscopic techniques to be in a position to provide fullspectrum treatment in the future.

\section{References}

1. Boeckxstaens GE, Annese V, des Varannes SB, Chaussade S, Costantini M, Cuttitta A, et al; European Achalasia Trial Investigators. Pneumatic dilation versus laparoscopic Heller's myotomy for idiopathic achalasia. N Engl J Med. 2011;364:1807-16.

2. Salvador R, Costantini M, Zaninotto G, Morbin T, Rizzetto C, Zanatta L, et al. The preoperative manometric pattern predicts the outcome of surgical treatment for esophageal achalasia. J Gastrointest Surg. 2010;14:1635-45.

3. Raja S, Murthy SC, Tang A, Siddiqui HU, Parikh MP, Ahmad U, et al. Per oral endoscopic myotomy: another tool in the toolbox. J Thorac Cardiovasc Surg. 2019;158:945-51.

4. Guo H, Yang H, Zhang X, Wang L, Lv Y, Zou X, et al. Long-term outcomes of peroral endoscopic myotomy for patients with achalasia: a retrospective singlecenter study. Dis Esophagus. 2017;30:1-6.

5. Zaninotto G, Bennett C, Boeckxstaens G, Costantini M, Ferguson MK, Pandolfino JE, et al. The 2018 ISDE achalasia guidelines. Dis Esophagus. 2018; 31(9).

6. Stavropoulos SN, Modayil R, Friedel D. Per oral endoscopic myotomy for the treatment of achalasia. Curr Opin Gastroenterol. 2015;31:430-40. 